\title{
Effects of inhibition on naming in aging
}

\author{
Efeitos da inibição na nomeação no envelhecimento
}

\author{
Yael Neumann \\ Queens College, City University of New York \\ Amy Vogel-Eyny \\ Graduate Center, City University of New York \\ Dalia Cahana-Amitay \\ VA Boston Healthcare System and Boston University School of Medicine

\section{Avron Spiro} \\ VA Boston Healthcare System, Boston University School of Public Health, Boston University School of Medicine, \\ and Goldman School of Dental Medicine \\ JungMoon Hyun \\ Graduate Center, City University of New York, VA Boston Healthcare System and Boston University School of Medicine \\ Martin L. Albert \\ VA Boston Healthcare System and Boston University School of Medicine \\ Loraine K. Obler \\ Graduate Center, City University of New York, VA Boston Healthcare System and Boston University School of Medicine
}

$\diamond$

\begin{abstract}
Findings regarding the relation between naming and inhibition among older adults is limited. We posited inhibitory control is crucial for successful naming and tested its role in older adults by exaggerating its effects. Participants included 215 older adults aged 55-89 years, categorized as "good" or "poor" namers, based on confrontation naming scores. Via a computerized speeded picture-naming test (SNT), we induced intrusions. We then determined the distance between the source for the intruding word and the current item. Performance on traditional neuropsychological tests of inhibition was also assessed. Results revealed that poorer namers had more intrusions on the SNT than better namers, and their intrusions lingered through more stimuli. This suggests that poorer namers experienced greater retrieval inhibition difficulties than better namers. Performance on neuropsychological tests of inhibition also discriminated between better and poorer namers. In conclusion, successful naming among older adults appears to rely heavily on maintaining inhibitory abilities.
\end{abstract}

Keywords: Intrusions; Speeded naming; Aging; Inhibitory control; Language.

Resumo: Os achados sobre a relação entre nomeação e inibição entre os idosos são limitados. Nós postulamos que o controle inibitório é crucial para a nomeação bem-sucedida e testamos seu papel em idosos, exagerando seus efeitos. Os participantes foram 215 idosos com idades entre 55-89 anos, categorizados como "bons" ou "pobres" nomeadores, com base em pontuações de nomeação. Através de um teste computadorizado de nomeação de imagens (SNT), induzimos intrusões. Determinamos então a distância entre a fonte da palavra intrusa e o item atual. O desempenho em testes neuropsicológicos tradicionais de inibição também foi avaliado. Os resultados revelaram que os mais nomeadores "pobres" tiveram mais intrusões no SNT do que os "bons", e suas intrusões permaneceram através de mais estímulos. Isso sugere que os nomeadores mais pobres experimentaram maiores dificuldades de inibição de recuperação do que os melhores nomeadores. O desempenho em testes neuropsicológicos de inibição também discriminou entre nomeadores melhores e mais pobres. Concluindo, a nomeação bem-sucedida entre os adultos mais velhos parece depender muito da manutenção de habilidades inibitórias.

Palavras-chave: Intrusões; Nomeação rápida; Envelhecimento; Controle inibitório; Linguagem. 


\section{Literature Review}

The Transmission Deficit Hypothesis (TDH) proposes that with age, the amount of priming and rate of transmission, i.e., the ease in selecting a target word from the lexical-semantic level and sending it to the phonological level in preparation for articulation, are reduced in any attempt at naming. This reduction particularly affects the most vulnerable nodes of a given word (i.e., the phonological ones). This vulnerability is attributed to the one-to-one connections that phonological nodes of a target have with lexical items in the network, as compared to semantic nodes of that target, which are highly interconnected. Because reinforcement of sounds at the level of phonological nodes is less extensive than that of words and concepts at the lexical/semantic-node level, the phonological-node level is highly susceptible to breakdowns in transmission of information (BURKE et al., 1991; JAMES; BURKE, 2000; MACKAY; ABRAMS, 1996).

Indeed, evidence from behavioral studies of older adults points to difficulty accessing the phonological form of the word, rather than earlier semantic (cf. BARRESI et al., 2000) or later articulation difficulties in the course of selecting and producing a given label for an object and/or action. Such findings are based on several areas of research including analyses of cues and primes that benefit older adults, error analyses, and the consistency of their naming responses across the adult lifespan (e.g., BARRESI et al., 2000; BOWLES; POON, 1985; JAMES; BURKE, 2000; NICHOLAS et al., 1985; OBERLE; JAMES, 2013). Brain-based studies have extended this argument further, most crucially in electrophysiological investigations of implicit naming abilities in healthy younger and older adults (e.g., NEUMANN; ALBERT; GOMES; SHAFER, 2009), suggesting that older adults have difficulties at both the syllabic and phonemic levels of phonology.

\section{Inhibitory control and aging}

Levelt and his colleagues (e.g., GARRETT, 1993; LEVELT, 2001) developed a generally accepted theory of lexical retrieval that assumes speakers generate a set of semantically related words before narrowing in to search for the lemma of the specific word they intend before searching for its phonological shape. However, the inhibition necessary to eliminate the imprecise items in older adults has not been studied. We thus posited an alternative account of changes in naming with aging that derives from the Inhibition Deficit Hypothesis (IDH; HASHER; ZACKS, 1988; HASHER; ZACKS; MAY, 1999). The IDH takes a more cognitive approach than the TDH, suggesting that the phenomenon of naming difficulties should be situated in the context of decreases across a variety of cognitive skills with advancing age, including selective attention (e.g., BRINK; MCDOWD, 1999) and working memory (e.g., ANDERSON; CRAIK, 2000; LEVITT, 2006). Thus, the IDH considers language as dependent on cognitive factors, most crucially inhibition. Our understanding of the role of inhibitory abilities in language processing developed in response to findings from a variety of studies investigating older adults' performance on tasks requiring inhibition of competing words (e.g., HEALEY; CAMPBELL; HASHER, 2008) in spoken-word recognition (e.g., DEY; SOMMERS, 2015; SOMMERS; DANIELSON, 1999) and topic regulation in conversation (e.g., ARBUCKLE; GOLD, 1993). Based on the IDH, which originally was proposed to account for attentional declines with aging, we posited that older adults' naming difficulties are due to a reduced efficiency in inhibiting competitor lexical items that causes interference in the selection of the correct word.

Retrieval inhibition, the ability to suppress competing alternatives when naming words, has been studied extensively in younger adults (e.g., BROWN; ZOCCOLI; LEAHY, 2005), with evidence from various paradigms, such as short-term, episodic, or semantic memory tasks (e.g., JOHNSON; ANDERSON, 2004; LEVY; ANDERSON, 2002; TULVING; ARBUCKLE, 1966), and semantic-based retrieval tasks (e.g., BLAXTON; NEELY, 1983) showing evidence of its effects on response time and accuracy. However, it has not been examined in depth in older adults on single-word retrieval tasks as Burke (1997) pointed out, despite their known difficulty with lexical retrieval. To our knowledge, studies of retrieval inhibition in the aging population are limited to investigations of visual word recognition and orthographic neighborhood frequency effects (STADTLANDER, 1995; ROBERT; MATHEY, 2007).

Thus, the purpose of this study was to investigate the relation between inhibitory control and word-naming abilities among older adults. In order to accomplish this goal, our research team devised a computerized Speeded picture-Naming Test (SNT; CONNOR et al., 2002; GORAL et al., 2007) that stresses inhibitory skills. The task manipulates duration of stimulus presentation and number and type of potential distractors, as it requires participants to retrieve the names of pictured items in a speeded condition with semantically close competitors among the stimuli. We reasoned that under such task constraints, participants may not take the time to select the correct word, but, rather, produce an intrusion, a nontarget word that is either a phonologically or semantically related word or word fragment (e.g., the first phoneme) from among the words previously presented for naming. In addition to measuring total correctness scores, one can 
measure the number of intrusions and the distance (in words) between the intruding word and the current item.

To minimize the possible effects of age-related decline in processing speed on our findings, as per theories of generalized cognitive slowing in older adults (see FEYEREISEN, 1997; SALTHOUSE, 1996, 2000), we calibrated the stimulus duration for each participant individually, based on their pre-testing response time results (see Methods). Stimulus duration was used as our measure of processing speed.

The two theoretical accounts presented above make the following predictions for SNT performance. The IDH predicts that the more words activated, the more difficulty poorer namers would have in inhibiting interfering activated competitors, and especially of earlier named intrusions, as compared to more recent ones. This is because the earlier items persist to interfere in the selection of the correct item as the IDH posits that difficulties arise on tasks that require the ability to suppress competing alternatives. Additionally, the IDH predicts poor performance on neuropsychological tests of inhibition for the poorer namers as it is specifically retrieval inhibition that is suspected to reduce naming efficiency in older adults.

The TDH, in contrast, predicts that naming difficulties in poorer namers would be related to deficits in priming between the lexical and phonological nodes. These deficits would be influenced by word recency as measured by lag distance in our study, such that poorer namers would have more intrusions of earlier, rather than recently, named items. This is because the TDH hypothesizes that lexical to phonological connections, especially phonological ones, are weakened with age and would be strengthened with activation of these nodes from recent naming of those items.

Our research questions were: (1) Is better naming among older adults, as measured by higher scores on the standardized confrontation naming test (the Boston Naming Test [BNT], GOODGLASS, KAPLAN; BARRESI, 2001), associated with better ability to inhibit lexical competitors, as measured by the frequency of intrusions on the SNT? We hypothesized that BNT performance would predict SNT performance; namely, that better namers in non-speeded conditions would have fewer intrusions on the SNT than poorer namers.

(2) Do SNT intrusions among poorer namers come from items presented earlier in the test, than intrusions among better namers? To answer this question, we measured the number of items between when a given intrusion occurred and the prior time it was named. We predicted that the average distance of intruding items of poorer namers would be from further back on the list than those of better namers, reflecting weak overall inhibition.
(3) Does performance on neuropsychological tests of inhibition predict performance on the SNT? We predicted that performance on the Stroop test (STROOP, 1935) and the difference measure of the Trails A and B task (SPREEN; STRAUSS, 1998), neuropsychological tasks widely considered to measure inhibition, would predict naming correctness and intrusion performance on the SNT. More specifically, we expected that low performance on the neuropsychological tasks would predict more intrusions in the SNT.

\section{Method}

The current study derives from a larger project, The Language in the Aging Brain study (ALBERT; OBLER, co-PIs) in which participants were administered an extensive battery of cognitive and language tasks over two sessions scheduled within six weeks from one another. In this study, we report findings from all participants who had data from the tasks below.

\section{Participants}

Two hundred and fifteen older participants (102 males, 113 females), aged 55-89 years (mean: 72.07 years, $\mathrm{SD}=7.94$ ), with a mean education of 15.1 years (range: 9-18 years, $\mathrm{SD}=1.94)$, were included in the study ${ }^{1}$. The participants provided written informed consent, approved by IRBs of both the Veterans Affairs Boston Healthcare System and the Boston University School of Medicine, prior to participation in the study.

\section{Measures}

Cognitive tests. The Stroop test and Trails A and B task are neuropsychological tasks that are commonly employed to assess inhibition. We reasoned that if inhibition ability contributed to naming performance, performance on both tests would predict SNT intrusions.

Stroop test. The Stroop test (STROOP, 1935), a wellaccepted index of inhibition (STRAUSS, SHERMAN; SPREEN, 2006), sets up a conflict between ink colors and written words. In the incongruent condition, the condition requiring most inhibition, color names are written in incongruent ink colors and participants are required to name the ink color, ignoring the printed word (e.g., they see the word 'blue' written in red ink and are to say 'red'.) In the congruent condition of our version, the word and the ink color match (e.g., participants see the word 'green'

\footnotetext{
1 This group overlaps substantially with the participants described in GORAL et al., 2011. See that paper for additional information on participant selection criteria.
} 
written in green ink). In our study, participants were asked to label the ink colors of as many items as possible within two minutes. The difference score between the errors made on the congruent from the incongruent condition (incongruent-congruent) was calculated.

Trails $\boldsymbol{A}$ and $\boldsymbol{B}$ task. Trails A and B (SPREEN; STRAUSS, 1998) is a task of executive functioning, specifically evaluating cognitive processing speed and task switching, skills which reflect the functioning of inhibition processes (ARNETT; LABOVITZ, 1995). In Trails A, the participant is asked to draw lines connecting in ascending order a series of numbered circles that are randomly scattered on a sheet of paper. In Trails B, the participant alternates connecting an equivalent number of circles with numbers and letters in them in order (e.g., $1, \mathrm{~A}, 2, \mathrm{~B} \ldots$ ) and must inhibit the tendency to follow A with B, or 2 with 3 . The difference scores for both errors and response time (RT) between Trails B and Trials A (Trails B - Trails A) were calculated.

Language tests. The BNT and SNT were administered to participants to assess naming skills. The $B N T$ is a standardized naming assessment of 60 black and white line drawings, administered via computer to assess both accuracy and latency. The $S N T$ was a test that our research team designed which included items taken from a subset of the Snodgrass and Vanderwart (1980) black and white picture set for which there was $75 \%$ name agreement or better. There were no overlapping pictures on the BNT and SNT. The SNT pictures were selected from six categories: five semantic categories (clothing, furniture, toys, four-footed animals, and birds), which contributed four items per category, and one group of five pictures that were semantically unrelated to each other and to any of the other categories. Thus 25 items were included (see Table 1). Based on Battig and Montague's (1969) category norms, each category consisted of one high-prototypical (HP) exemplar and three lowprototypical (LP) items. In their norms, prototypicality denotes the frequency with which raters generated each item when asked to generate words in a category (e.g., birds). The HP items ranged from 1 (most frequently generated for its category) to 5; the LP items were ranked higher than 10 . The semantically unrelated category included pictures that were either LP or not included in the Battig and Montague category norms. Additionally, the stimuli were selected such that no two items shared an initial phoneme.

The distance between LP and HP targets varied. Each of the five HP exemplars (i.e., horse, eagle, ball, table, and shirt) appeared 36 times, while each of the 15 LP exemplars appeared three times (once at each of three distances: either immediately following, with two items between, or with four items between itself and its HP prime), and each of the semantically unrelated items appeared four times. This yielded a total of 245 trials, including $180 \mathrm{HP}$ exemplar targets, $45 \mathrm{LP}$ exemplar targets, and 20 semantically unrelated ones.

All participants received an identical order of presentation, with an average inter-stimulus interval (ISI) of $333 \mathrm{~ms}$ (319 ms after picture offset a beep was heard and $14 \mathrm{~ms}$ later the next picture was presented). Stimulus duration and inter-stimulus intervals were based on individual calibration times as described below.

The SNT was administered in three phases: (1) Training, (2) Calibration, and (3) Testing. A DAT/ CD recorder was linked to the EPrime program (range of timing variability was $20 \mathrm{~ms}$ ) that presented the materials used for calibration and the SNT trials.

(1) In the training phase, our goal was to assure that participants were using the established target names for each picture. The phase consisted of three parts. First, the participants listened as they looked at each of the 25 target pictures for two seconds, and the examiner named the items and then pressed the space bar to display the next item. Next, the examiner showed the list again and the participant joined in naming the items aloud. Finally, the examiner showed each pictured item and the participant named the targets alone. Throughout the demonstration the examiner corrected the rare mistakes made by the participant.

Table 1. Speeded Naming Test Items

\begin{tabular}{cccccc}
\hline Four-legged animals & Types of birds & Types of toys & Household items & Pieces of clothing & $\begin{array}{c}\text { Semantically } \\
\text { unrelated* }\end{array}$ \\
\hline Horse & Eagle & Ball & Table & Shirt & Flag \\
Deer & Owl & Wagon & Stool & Glove & Iron \\
Giraffe & Penguin & Kite & Clock & Boot & Lemon \\
Zebra & Duck & Drum & Piano & Vest & Anchor \\
& & & & & Mushroom \\
\hline
\end{tabular}

Note: These categories were used to consider whether an intrusion was of the "same-category" or "different category". Italic items refer to high-prototypical category exemplars. The remaining items are low-prototypical category exemplars.

*These are NOT semantically related to each other or any other item on the list. 
(2) The calibration trials were employed to determine individual stimulus presentation times and inter-stimulus intervals to control for inter-individual variability in processing speed, so that the task would not be more difficult for slower participants. This was an important part of the design that allowed us to tailor the SNT task to individual performance and reduce the influence of agerelated cognitive slowing. For most participants, there were two calibration trials, in order to acclimate them to the task's requirement of speeded naming. During the first trial, participants were asked to press the space-bar and name the pictures as quickly as possible, without any hesitations (e.g., "ah" or "um") lest the microphone pick up the response and the picture would advance. After the first trial, participants were corrected for any responses that differed from the target. During the second trial, participants were again asked to name the pictures as quickly as possible, and it was similarly self-paced in that the participant pressed the space bar for each new item, as was done in the first trial. Voice-activated relay was employed to determine reaction time (RT) for each item. Performance on this trial was used to generate the stimulus-duration time for the actual testing. However, if there were more artifacts in the second calibration trial than in the first one, then data from the first calibration trial were used. If both trials were corrupted, then a third calibration trial was run. For sixteen participants, all three calibration trials were corrupted; in those cases, data from the least corrupted trial was used. Examples of artifacts included: the microphone not picking up three or more of the participant's responses (in which case RT would be inaccurately slow), the participants lagging behind in their naming (i.e., naming a previous picture while a new picture was on the screen, in which case RT would be inaccurately fast).

Stimulus duration for each participant was calculated from the trial with the fastest average RT. Inter-stimulus interval (ISI) was calculated by multiplying the participant's unique stimulus duration time, i.e. average RT, by 0.5 .

(3) The final part of the experiment was the actual speeded naming test. Participants saw the same pictures at their calibrated rates and were told to name them as quickly as possible before the sound of a beep that followed each picture. Participants were told that it was most important to respond quickly regardless of response accuracy. The examiner did not correct any mistakes made on the target items.

\section{Transcription}

Responses were recorded and transcribed verbatim, including intrusions, fillers, and/or conversational comments made by the participant. Time (on/before or after the beep) was recorded in E-prime for all responses, noting any partial responses (e.g., stutters). If any part of the response (whether correct or incorrect) overlapped with the beep, it was considered "on or before the beep," even if the participant just started to say something when the beep sounded.

Coding of SNT. Responses were coded as correct if they were accurate and occurred prior to the beep tone or if they were accurate and occurred before or after the beep tone with one or more intrusions (e.g., if a participant said 'ay-uh-shirt, vest' for the target word vest, 'ay-uh' was scored as a phoneme-only intrusion, 'shirt' as a same-category intrusion, and 'vest' as a correct response). Responses were coded as incorrect if they were inaccurate before or after the beep tone.

Interrater reliability. The transcription and coding judgments were compared between two raters who undertook both transcribing and coding. Several passes through coding were made in order to refine our definitions of each category. The data analyzed in this paper are from the final scoring where the average interrater reliability was $r=.892$.

\section{Statistical Analyses}

Correlation and multiple regression analyses were conducted to assess relations between inhibition and speeded naming. In all outcome variables, participants who fell \pm 3.5 SD from the mean were removed from the analyses of that given task. More specifically, to address the first research question, analyses were conducted between naming skill on the BNT and SNT percent intrusions, covarying age, gender, education, and processing speed. The independent variable was percent accuracy on the BNT, and the dependent variable was the percentage of intrusions made on the SNT. To address the second research question, accuracy scores on the BNT were dichotomized to divide participants into better and poorer namers, to permit comparisons of SNT performance (i.e., intrusion distance) between these two groups. The better namers were the 80 participants who performed above the BNT norms for healthy older adults of their age decade, and the poorer namers were those 135 who performed below the BNT norms (TOMBAUGH; HUBIEY, 1997). See Table 2 for summary of age, education, gender, and processing speed of better and poorer namers. An independent samples t-test was employed to determine whether better and poorer namers differed in the average distance of intrusions from their prior occurrence on the SNT. 
Table 2. Age, Education, Gender, and Processing Speed for the Better and Poorer Namers

\begin{tabular}{|c|c|c|c|c|c|}
\hline Participants' Naming Ability & $\mathbf{N}$ & Mean Age Yrs. (SD) & Mean Education Yrs. (SD) & Gender & Processing Speed ms (SD) \\
\hline Better Namers & 80 & $71.93(8.02)$ & $15.23(1.80)$ & $\begin{array}{c}\text { Male }=47 \\
\text { Female }=33\end{array}$ & $476.84(66.47)$ \\
\hline \multirow[t]{2}{*}{ Poorer Namers } & 135 & $72.16(7.92)$ & $15.02(2.02)$ & $\begin{array}{c}\text { Male }=55 \\
\text { Female }=80\end{array}$ & $513.71(98.50)$ \\
\hline & & $p=.837$ & $p=.459$ & $p=.010$ & $p=.004$ \\
\hline
\end{tabular}

Note: Participants were divided into two categories based on individuals' ages and scores according to the Boston Naming Test norms for healthy older adults (Tombaugh and Hubiey, 1997).

Lastly, in order to investigate research question three, the relation between neuropsychological tests of inhibition (i.e., the Stroop test and Trails A and B) and SNT percent intrusions was explored through multiple regression analyses. We examined whether the number of errors made on the Stroop task and Trails A and B predicted SNT percent intrusions.

\section{Results}

\section{SNT Performance}

As a group, participants performed as our calibration of exposure times intended, almost at ceiling in the SNT (98\%; mean correct: 239.74 out of a possible 245 trials; SD: 6.71 ; range: 189 to 245 ) with a group total number of 50,106 correct responses and 1,316 (range: 0 to 56) incorrect responses. They had a mean percent intrusion rate of 3.84 (SD: 2.79; range: 0 to 13 ) with a group total of 1,912 raw intrusions (range of total raw intrusions across group: 0 to 30). Interestingly, although $98 \%$ of participants performed at ceiling, only $6 \%$ of participants made no intrusions at all. Thus, overall the vast majority of participants had at least one intrusion even though the total number of intrusions they made was small.

\section{Naming ability and SNT performance}

The first research question was whether better naming among older adults is associated with a better ability to inhibit lexical competitors. First we note that percent accuracy on the BNT and SNT intrusions were correlated $(\mathrm{r}=-.328, p<.001)$. We were further interested in the relation between lexical retrieval performance on the BNT and the possible inhibitory difficulties associated with retrieval, as measured by intrusions, on the SNT. A multiple regression analysis, covarying age, education, gender and processing speed revealed that both BNT percent accuracy $(\beta=-.374, t(187)=-5.268, p<.001)$ and SNT processing speed $(\beta=-.174, t(187)=-2.430, p<.05)$ were negatively associated with SNT percent intrusions, i.e., poorer naming on the BNT and slower responding on the SNT predicted greater SNT \% intrusions.

\section{Naming Ability and Intrusion Distance}

The second research question was whether intrusions in poorer namers come from items presented less recently than those in better namers, The mean lag distance of the intrusion, the distance between the occurrence of a given intrusion and its prior mention during testing (either correctly or as an intrusion), was 8.73 items, however, there was great variability in the lag distance values, between and within groups ( $\mathrm{SD}=8.37)$. When looking at the log-transformed distance of intrusion sources, the mean distance was longer for the poorer namers $(\mathrm{M}=8.32$, $\mathrm{SD}=2.60)$ than for the better namers $(\mathrm{M}=.4 .40, \mathrm{SD}=.2 .32)$, $(t(209)=4.90, p<.001)$.

\section{Relationship between Inhibitory Control Measures and Intrusions}

The third research question was whether performance on the neuropsychological tests of inhibition predicts performance on the SNT. For the Trails and Stroop Tests, Z-Scores were calculated and participants who fell $+/-3.5$ $\mathrm{SD}$ from the mean were removed from the analyses (Trails RT: $n=2$; Trails Accuracy: $n=0$; Stroop: $n=3$ ). A multiple regression analysis covarying age, education, gender, and processing speed showed that the difference between the two Trails conditions' RT did not significantly predict SNT $\%$ intrusions $(\beta=.122, t(182)=1.49, p=.107)$; however, the difference in errors between the two conditions was a significant predictor of SNT percent intrusions (Trails B - Trails A; $\beta=.165, t(184)=2.245, p<.05$ ), i.e., more errors on the Trails predicted a higher percentage of SNT intrusions. The Stroop Test predicted SNT percent intrusions in that the multiple regression analysis showed that the difference between the errors made on the congruent and incongruent conditions (incongruentcongruent) predicted SNT percent intrusions $(\beta=-.154$, $t(175)=-2.054, p<.05)$, i.e., lower accuracy on the Stroop predicted a higher percent of SNT intrusions. See Table 3 and $\mathbf{4}$ for multiple regression analyses for the Trails and Stroop tasks. Correlations between all outcome variables in the study are presented in Table 5, and descriptive statistics of all measures are shown in Table 6. 
Table 3. Summary of Multiple Regression Analysis of Trails Error Difference Predicting SNT Percent Intrusions

\begin{tabular}{|c|c|c|c|c|c|}
\hline Variables & B & SE B & $\beta$ & $\mathbf{t}$ & p \\
\hline Constant & 2.716 & 2.861 & & .95 & .344 \\
\hline Age & .038 & .028 & .109 & 1.386 & .167 \\
\hline Education & -.059 & .111 & -.039 & -.531 & .596 \\
\hline Gender & .188 & .428 & .033 & .44 & .661 \\
\hline Processing Speed & -.002 & .002 & -.062 & -.819 & .414 \\
\hline Trails Errors Difference & .556 & .248 & .165 & 2.249 & .026 \\
\hline
\end{tabular}

Note: $\mathrm{R}^{2}=.052$.

Table 4. Multiple Regression Analysis of Stroop Correct Difference Predicting SNT Percent Intrusions

\begin{tabular}{|c|c|c|c|c|c|}
\hline Variables & B & SE B & $\beta$ & $\mathbf{t}$ & $\mathbf{p}$ \\
\hline Constant & -.064 & 2.966 & & -.021 & .983 \\
\hline Age & .049 & .028 & .14 & 1.73 & .085 \\
\hline Education & -.033 & .112 & -.022 & -.298 & .766 \\
\hline Gender & .317 & .438 & .055 & .724 & .47 \\
\hline Processing Speed & -.002 & .003 & -.069 & -.886 & .377 \\
\hline Stroop Correct Difference & -.013 & .006 & -.154 & -2.054 & .041 \\
\hline
\end{tabular}

Note: $\mathrm{R}^{2}=.06$

Table 5. Correlations among Age, Education, Gender, Processing Speed, and All Measures

\begin{tabular}{|c|c|c|c|c|c|c|c|c|c|c|}
\hline Variables & Age & Education & Gender & $\begin{array}{l}\text { Processing } \\
\text { Speed }\end{array}$ & $\begin{array}{l}\text { BNT \% } \\
\text { Correct }\end{array}$ & $\begin{array}{l}\text { SNT \% } \\
\text { Intrusion }\end{array}$ & $\begin{array}{l}\text { Intrusion } \\
\text { Distance }\end{array}$ & $\begin{array}{c}\text { Trails RT } \\
\text { Difference }\end{array}$ & $\begin{array}{l}\text { Trails Error } \\
\text { Difference }\end{array}$ & $\begin{array}{c}\text { Stroop } \\
\text { Correct } \\
\text { Difference }\end{array}$ \\
\hline Age & 1 & & & & & & & & & \\
\hline Education & $-.18^{* *}$ & 1 & & & & & & & & \\
\hline Gender & $.19^{* *}$ & -.07 & 1 & & & & & & & \\
\hline Processing Speed & $-.28^{* *}$ & -.07 & -.09 & 1 & & & & & & \\
\hline BNT \% Correct & $.15^{\star}$ & $.19^{\star *}$ & $.15^{*}$ & $-.25^{\star *}$ & 1 & & & & & \\
\hline SNT \% Intrusion & $.14^{*}$ & -.05 & -.09 &.- .02 & $-.31^{* *}$ & 1 & & & & \\
\hline Intrusion Distance & .10 & -.08 & -.12 & $.22^{*}$ & $-.31^{*}$ & $.19^{\star *}$ & 1 & & & \\
\hline Trails RT Difference & $.15^{*}$ & -.12 & .12 & $.15^{*}$ & $-.16^{*}$ & .13 & .12 & 1 & & \\
\hline Trails Errors Difference & $-.14^{*}$ & -.00 & .05 & .07 & -.09 & $.17^{*}$ & .02 & $.41^{\star *}$ & 1 & \\
\hline Stroop Correct Difference & $-.18^{*}$ & -.00 & -0.3 & -.01 & .13 & $-.16^{*}$ & .05 & -.06 & -.11 & 1 \\
\hline
\end{tabular}

*Correlation significant at .05 (2-tailed); **Correlation significant at .01 (2-tailed).

Table 6. Descriptive Statistics for All Measures

\begin{tabular}{|c|c|c|c|c|c|}
\hline Measures & $\mathbf{N}$ & Minimum & Maximum & Mean & SD \\
\hline BNT Percent Correct & 214 & 53 & 100 & 84.77 & 9.54 \\
\hline Better Namers & 80 & 87 & 100 & 92.40 & 3.19 \\
\hline Poorer Namers & 134 & 53 & 93 & 78.62 & 8.26 \\
\hline SNT Percent Intrusion & 209 & 0 & 13 & 3.84 & 2.79 \\
\hline Better Namers & 80 & 0 & 13 & 3.23 & 2.75 \\
\hline Poorer Namers & 129 & 0 & 13 & 4.22 & 2.75 \\
\hline Intrusions Distance & 211 & 1 & 38.90 & 6.54 & 2.62 \\
\hline Better Namers & 80 & 1 & 28.84 & 4.40 & 2.32 \\
\hline Poorer Namers & 131 & 1 & 38.90 & 8.32 & 2.61 \\
\hline Trails RT Difference & 209 & 1 & 138 & 46.47 & 26.09 \\
\hline Better Namers & 79 & 7 & 126 & 41.52 & 23.16 \\
\hline Poorer Namers & 130 & 1 & 138 & 49.48 & 27.36 \\
\hline Trails Errors Difference & 211 & -2 & 3 & 0.41 & 0.86 \\
\hline Better Namers & 79 & -1 & 3 & 0.29 & 0.75 \\
\hline Poorer Namers & 132 & -2 & 3 & 0.48 & 0.92 \\
\hline Stroop Correct Difference & 201 & -273 & -56 & -150.48 & 35.69 \\
\hline Better Namers & 73 & -231 & -56 & -146.00 & 33.05 \\
\hline Poorer Namers & 128 & -273 & -67 & -153.04 & 37.00 \\
\hline Processing Speed & 199 & 357 & 982.26 & 499.63 & 89.30 \\
\hline Better Namers & 76 & 357 & 729.28 & 476.83 & 66.48 \\
\hline Poorer Namers & 123 & 362.60 & 982.26 & 513.71 & 98.50 \\
\hline
\end{tabular}




\section{Discussion}

Prior research by Burke and her team (e.g., BURKE et al., 1991; BURKE and SHAFTO, 2008) has confirmed the TDH: that the difficulty older adults show with lexical retrieval arises after the semantic level in the location of the phonological shape of the target word. We hypothesized that a complementary alternative must be considered: the IDH that the difficulty that interferes with older adults' retrieval of the phonological shape of a word arises from problems inhibiting related words.

We created a speeded naming task to stress inhibition during lexical retrieval and asked first whether lexical retrieval on the BNT predicts performance on our SNT. We expected better namers to have fewer intrusions on the SNT than poorer namers, due to better lexical-retrieval inhibition skills. Our findings corroborated our prediction and are consistent with a role for inhibition in lexical retrieval, in line with the IDH. This suggests that inhibition, as measured by intrusions on the SNT, contributes to successful naming with age and is in line with prior research of retrieval inhibition with younger adults indicating that reduced efficiency in inhibitory control results in more lexical items interfering in the naming process (e.g., BROWN et al., 2005). This inhibition account is typically explained as being due to one of two sources: 1) interference from retrieval of prior exemplars, as activated items continue to dominate, making it more difficult to retrieve other exemplars within the same category, and/or 2) suppression or weakening of activation of exemplars that were not retrieved in an attempt to more easily access the target word.

Additionally, the covariate of processing speed negatively predicted SNT percent intrusions, even though we calibrated the stimulus duration and inter-stimulus interval for each individual participant based on their pre-testing response time results. This result is consistent with prior research findings demonstrating a role that processing speed plays in explaining age-related declines in working memory, as per theories of generalized cognitive slowing (see EARLES, CONNOR, SMITH; PARK, 1997; FEYEREISEN, 1997; PARK et al., 1996; SALTHOUSE, 1994, 1996, 2000). Although processing speed has been linked to many types of memory in aging, clearly memory for the lexical items to be spoken is required for a naming task. Whether it is long-term memory of items' names, or a shorter-term memory of the words reviewed before the testing, it appears that processing speed predicts retrieval of the targets from memory storage in the population we tested.

The second research question investigated the influence of competition on retrieval due to prior instances of naming the intruding item. We predicted that poorer namers, as compared to better namers, would produce intrusions of items presented further-back since they have weaker inhibition skills of even less recently named items, consistent with the IDH. Our findings supported this hypothesis. On average, poorer namers produced intrusions that had lingered through many more stimuli (11.00) than those of better namers (5.00), suggesting that lingering activation that is not inhibited can interfere with lexical retrieval in older adults. This interference from competing words seen in the naming abilities of poorer namers appears similar to the underlying pathological mechanism that produces the phenomenon of perseveration in the language impairments of poststroke aphasia, although in aphasia there is an additional aspect of weak activation of the target word due to the language deficits (e.g., MARTIN; Dell, 2007; MARTIN; Dell, 2004; MARTIN; ROACH; BRECHER; LOWERY, 1998).

In particular, we posit that lingering intrusions from far-distant items in the poorer namers reflect a difficulty in updating working memory, an independent aspect of executive functioning. Updating involves monitoring and coding streaming information in order to replace no longer relevant information that is held in working memory, with new, relevant information. (e.g., MORRIS; JONES, 1990; MIYAKE, et al., 2000). It appears that the poorer namers not only had difficulty in inhibiting interfering items that had been previously activated but also had difficulty in replacing the wrongly-selected items with the new target items. We suspect that among poorer namers this problem arises because previous items do not get erased well, and so linger longer, leading to more interference. This impairment in memory updating has been previously reported in the aging literature for both verbal (DE BENI; PALLADINO, 2004; VAN DER LINDEN; BREDART; BEERTEN, 1994) and visuospatial (FIORE; BORELLA; MAMMARELLA; DE BENI, 2012) working memory tasks.

Additionally, our findings that even most better namers had intrusions, primarily on recently presented items, demonstrate the recency effect, as posited in the $\mathrm{TDH}$, that is, that recently retrieved words are currently retrieved more easily for naming. This is because there is heightened activation for the phonological shapes of these recently retrieved words, which is the hypothesized locus of deficit for healthy older adults. In the current paradigm, of course, activated recent items should be inhibited, but even for good namers this did not always occur.

Finally, the third research question investigated the indirect role of inhibition on naming. For the two standardized neuropsychological tests of inhibition 
(Trails A and B and Stroop) we hypothesized that poorer performance would predict more intrusions on the SNT. Our findings confirmed this prediction aligning with the strong indications of inhibition problems evidenced among our older-adult population on our SNT test. Taken together, the evidence suggests that inhibition plays an important role in the determination of naming ability associated with advancing age, in line with the IDH. We further suggest that the SNT, by taxing both spoken picture naming and inhibitory skills in one task, is a unique tool to predict age-related naming abilities.

A possible limitation of our study is the low overall number of intrusions $(X=3.84)$ that participants made on the SNT, although we note that only $6 \%$ of our participants made no intrusions at all. The number of significant correlations we found despite this low range of errors is, we would argue, all-the-more compelling.

\section{Conclusions}

We conclude that naming difficulties among the elderly are linked to worsened inhibitory control and working memory updating. Thus, our intrusion findings support the IDH and complement the TDH, portraying reduced inhibitory functioning as a significant contributor to lexical retrieval, prior to, or concurrent with, the difficulties with retrieving the target's phonological wordshape.

Older adults select numerous cognitive games to enhance their cognitive abilities these days. For those concerned about lexical retrieval problems, our findings suggest clinicians should encourage them not only to focus on strengthening phonological linguistic skills (e.g., identifying number of syllables, initial and final phonemes, rhymes, etc. for target items which they experience naming failure on) but also to work on skills to strengthen inhibition abilities (e.g., ignoring distractions, focusing on task-relevant stimuli.

\section{References}

ABRAMS, L.; TRUNK, D. L.; MARGOLIN, S. J. Resolving tip-of-the-tongue states in young and older adults: The role of phonology. In: RANDAL, L. O. (Ed.), Aging and the Elderly: Psychology, Sociology, and Health. Hauppauge, NY: Nova Science Publishers, Inc., 2007. p. 1-41.

ALBERT, M. S.; HELLER, H. S.; MILBERG, W. Changes in naming ability with age. Psychology and Aging, v. 3, p. 173-178, 1988.

ANDERSON, N. D.; CRAIK, F. I. M. Memory in the aging brain. In: TULVING, E.; CRAIK, F. I. M. (Eds.). The Oxford Handbook of Memory. New York: Oxford University Press, 2000.

ARBUCKLE, T. Y.; GOLD, D. P. Aging, inhibition, and verbosity. Journal of Gerontology, 48, 225-232, 1993.
ARDILA, A.; ROSSELLI, M. Neuropsychological characteristics of normal aging. Developmental Neuropsychology, v. 5, p. 307-320, 1989.

ARNETT, J. A.; LABOVITZ, S. S. Effect of physical layout in performance of the Trail Making Test. Psychological Assessment, v. 7, p. 220-221, 1995.

AU, R.; JOUNG, P.; NICHOLAS, M.; OBLER, L. K.; KASS, R.; ALBERT, M. L. Naming ability across the adult life span. Aging and Cognition, v. 2, p. 300-311, 1995.

BARRESI, B. A.; NICHOLAS, M.; CONNOR, L. T.; OBLER, L. K.; ALBERT, M. L. Semantic degradation and lexical access in age-related naming failures. Aging, Neuropsychology, and Cognition, v. 7, p. 169-178, 2000.

BATTIG, W. F.; MONTAGUE, W. E. Category norms of verbal items in 56 categories: A replication and extension of the Connecticut category norms. Journal of Experimental Psychology, v. 80, p. 1-46, 1969.

BLAXTON, T. A.; NEELY, J. H. Inhibition from semantically related primes: Evidence of a category-specific inhibition. Memory and Cognition, v. 11, p. 500-510, 1983.

BOWLES, N. L.; POON, L. W. Aging and retrieval of words in semantic memory. Journal of Gerontology, v. 40, p. 71-77, 1985.

BOWLES, N. L.; OBLER, L. K.; ALBERT, M. L. Naming errors in aging and dementia of the Alzheimer type. Cortex, v. 23 , p. $519-524,1987$.

BRINK, J. M.; MCDOWD, J. M. (Aging and selective attention: An issue of complexity or multiple mechanisms? Journals of Gerontology. Series B: Psychological Sciences and Social Sciences, v. 54, p. 30-33, 1999.

BROWN, A. A review of the tip-of-the-tongue experience. Psychological Bulletin, v. 109, p. 204-223, 1991.

BROWN, A. S.; ZOCCOLI, S. L.; LEAHY, M. M. Cumulating retrieval inhibition in semantic and lexical domains. Journal of Experimental Psychology: Learning, Memory, and Cognition, v. 31, p. 496-507, 2005.

BURKE, D. M. Language, aging, and inhibitory deficits: Evaluation of a theory. Journal of Gerontology: Psychological Sciences, v. 52B, p. 254-264, 1997.

BURKE, D. M.; MACKAY, D. G.; WORTHLEY, J. S.; WADE, E. On the tip of the tongue: What causes word finding failures in young and older adults? Journal of Memory and Language, v. 30, p. 542-579, 1991.

BURKE, D. M.; SHAFTO, M. A. Language and aging. In: CRAIK, Fergus I. M.; SALTHOUSE, Timothy A. (Eds.). The handbook of aging and cognition. New York: Psychology Press, 2008. p. 373-443.

CONNOR, L. T.; MACKAY, A. J.; SCHALMAN-BERGEN, S.; FOURNIER, J. C.; OBLER, L. K.; ALBERT, M. L. Rapid picture naming: Age differences in suppressing competitors. Poster presented at the meeting of the Cognitive Aging Conference, Atlanta, GA, 2002.

DE BENI, R.; PALLADINO, P. Decline in working memory updating through ageing: Intrusion error analyses. Memory, v. 12, p. 75-89, 2004.

DEY, A.; SOMMERS, M. S. Age-related differences in inhibitory control predict audiovisual speech perception. Psychology and Aging, v. 30, p. 634-646, 2015. 
EARLES, J. L.; CONNOR, L. T.; SMITH, A. D.; PARK, D. C. Interrelations of age, self-reported health, speed, and memory. Psychology and Aging, v. 12, p. 675-683, 1997.

FEYEREISEN, P. A meta-analytic procedure shows an agerelated decline in picture naming: Comments on Goulet, Ska, and Kahn. Journal of Speech and Hearing Research, v. 40, p. $1328-1333,1997$.

FIORE, F.; BORELLA, E.; MAMMARELLA, I. C.; DE BENI, $\mathrm{R}$. Age differences in verbal and visuo-spatial working memory updating: Evidence from analysis of serial position curves. Memory, v. 20, p. 14-27, 2012.

GARRETT, M. Disorders of lexical selection. In: LEVELT, W. J. M. (Ed.). Lexical access in speech production. Cambridge, MA: Blackwell, 1993. p. 143-180.

GORAL, M.; SPIRO III, A.; ALBERT, M. L.; OBLER, L. K.; CONNOR, L. T. Change in lexical retrieval skills in adulthood. The Mental Lexicon, v. 2, p. 215-238, 2007.

GORAL, M.; CLARK-COTTON, M.; SPIRO III, A.; OBLER, L. K.; VERKUILEN, J.; ALBERT, M. The contribution of set switching and working memory to sentence processing in older adults. Experimental Aging Research, v. 37, p. 516-538, 2011.

HASHER, L.; ZACKS, R. T. Working memory, comprehension, and aging: A review and new view. In: BOWER, G. H. (Ed.). The psychology of learning and motivation: Advances in research and theory. New York: Academic Press, 1988. Vol. 22. p. 193-225.

HASHER, L.; ZACKS, R. T.; MAY, C. P. Inhibitory control, circadian arousal, and age. In: GOPHER, D.; KORIAT, A. (Eds.). Attention \& Performance, XVII, Cognitive Regulation of Performance: Interaction of Theory and Application. Cambridge, MA: MIT Press, 1999. p. 653-675.

HEALEY, M. K.; CAMPBELL, K. L.; HASHER, L. Chapter 22 cognitive aging and increased distractibility: Costs and potential benefits. Progress in Brain Research, v. 169, p. 353$363,2008$.

JAMES, L. E.; BURKE, D. M. Phonological priming effects on word retrieval and tip-of-the-tongue experiences in young and older adults. Journal of Experimental Psychology: Learning, Memory, and Cognition, v. 26, p. 1378-1391, 2000.

JOHNSON, S. K.; ANSERSON, M. C. The role of inhibitory control in forgetting semantic knowledge. A Journal of the Association for Psychological Science, v. 15, p. 448-453, 2004.

LE DORZE, G.; DUROCHER, J. The effects of age, educational level, and stimulus length on naming in normal subjects. Journal of Speech-Language Pathology and Audiology, v. 16, p. 21-29, 1992.

LEVELT, W. J. M. Spoken word production: A theory of lexical access. PNAS, v. 98, n. 23, p. 13464-13471, 2001.

LEVITT, T. Processing speed, attentional capacity, and agerelated memory change. Experimental Aging Research, v. 32, p. 263-295, 2006.

LEVY, B. J.; ANDERSON, M. C. Inhibitory processes and the control of memory retrieval. Trends in Cognitive Sciences, v. 6, p. 299-305, 2002.

MACKAY, D. G.; ABRAMS, L. Language, memory, and aging: Distributed deficits and the structure of new-versus-old connections. In: BIRREN, J. E.; SCHAIE, K. W.; ABELES, R. P.; GATZ, M.; SALTHOUSE, T. A. (Eds.). The handbooks of aging. Handbook of the psychology of aging. San Diego, CA: Academic Press, 1996. p. 251-265.

MACKAY, D. G.; BURKE, D. M. Cognition and aging: A theory of new learning and the use of old connections. In: HESS, T. M. (Ed.). Aging and cognition: Knowledge organization and utilization. Amsterdam: North-Holland, 1990. p. 213-263.

MARTIN, N.; DELL, G. S. Perseverations and anticipations in aphasia: Primed intrusions from the past and future. Seminars in Speech and Language Pathology, v. 25, p. 349-362, 2004.

MARTIN, N.; DELL, G. S. Common mechanisms underlying perseverative and non-perseverative sound and word substitutions. Aphasiology, v. 21, p. 1017-1992, 2007.

MARTIN, N.; ROACH, A.; BRECHER, A.; LOWERY, J. Lexical retrieval mechanisms underlying whole-word perseveration errors in anomic aphasia. Aphasiology, v. 12, p. 319-333, 1998.

MORRIS, N.; JONES, D. M. Memory updating in working memory: The role of the central executive. British Journal of Psychology, v. 81, p. 111-121, 1990.

MIYAKE, A.; FRIEDMAN, N. P.; EMERSON, M. J.; WITZKI, A. H.; HOWERTER, A.; WAGER, T. D. The unity and diversity of executive functions and their contributions to complex "frontal lobe" tasks: A latent variable analysis. Cognitive Psychology, v. 41, p. 49-100, 2000.

NEUMANN, Y.; OBLER, L. K.; GOMES, H.; SHAFER, V. Phonological vs sensory contributions to age effects in naming: An electrophysiological study. Aphasiology, v, 23, p. 10281039, 2009.

NICHOLAS, M.; OBLER, L.; ALBERT, M.; GOODGLASS, H. Lexical retrieval in healthy aging. Cortex, v. 21, p. 595-606, 1985 .

OBERLE, S.; JAMES, L. E. Semantically- and phonologicallyrelated primes improve name retrieval in young and older adults. Language and Cognitive Processes, v, 28, p. 1378-1393, 2013. doi: 10.1080/01690965.2012.685481

PARK, D. C.; SMITH, A. D.; LAUTENSCHLAGER, G.; EARLES, J. L.; FRIESKE, D.; ZWAHR, M. D.; GAINES, C. Mediators of long-term memory performance across the life span. Psychology and Aging, v. 11, p. 621-637, 1996.

POON, L. W.; FOZARD, J. L. Speed of retrieval from longterm memory in relation to age, familiarity, and datedness of information. Journal of Gerontology, v. 33, p. 711-717, 1978 .

RASTLE, K. G.; BURKE, D. M. Priming the tip of the tongue: Effects of prior processing on word retrieval in young and older adults. Journal of Memory and Language, v. 35, p. 586-605, 1996.

ROBERT, C.; MATHEY, S. Aging and lexical inhibition: The effects of orthographic neighborhood frequency in young and older adults. Journal of Gerontology: Psychological Sciences, v. 62B, 340-342, 2007.

SALTHOUSE, T. A. The processing-speed theory of adult age differences in cognition. Psychological Review, v. 103, p. 403-428, 1996. 
SALTHOUSE, T. A. The nature of the influence of speed on adult age differences in cognition. Developmental Psychology, v. 30, p. 240-259, 1994.

SALTHOUSE, T. A theory of cognitive aging. New York: Elsevier Science, 2000.

SNODGRASS, J. G.; VANDERWART, M. A standardized set of 260 pictures: Norms for name agreement, image agreement, familiarity, and visual complexity. Journal of Experimental Psychology: Human Learning and Memory, v. 6, p. 174-215, 1980.

SOMMERS, M. S.; DANIELSON, S. M. Inhibitory processes and spoken word recognition in young and older adults: The interaction of lexical competition and semantic context. Psychology and Aging, v. 14, p. 458-472, 1999.

SPREEN, O.; STRAUSS, E. A compendium of neuropsychological tests: Administration, norms, and commentary. 2. ed. London: Oxford University Press, 1998.

STADTLANDER, L. M. Age differences in orthographic and frequency neighborhoods. Advances in Psychology, v. 110, p. 72-86, 1995.

STRAUSS, E.; SHERMAN, E. M. S.; SPREEN, O. A compendium of neuropsychological tests: Administration, norms, and commentary. 3· ed. New York: Oxford University Press, 2006.
STROOP, J. R. Studies of interference in serial verbal reactions. Journal of Experimental Psychology, v. 18, p. 643-662, 1935.

THOMAS, J. C.; FOZARD, J. L.; WAUGH, N. C. Age-related differences in naming latency. The American Journal of Psychology, p. 499-509, 1977.

TOMBAUGH, T. N.; HUBIEY, A. M. The 60-item Boston Naming Test: Norms for cognitively intact adults aged 25 to 88 years. Journal of Clinical and Experimental Neuropsychology, v. 19, p. 922-932, 1997.

TULVING, E.; ARBUCKLE, T. Y. Input and output interference in short-term associative memory. Journal of Experimental Psychology, v. 72, p. 145-150, 1966.

VAN DER LINDEN, M.; BRE'DART, S.; BEERTEN, A. Age-related differences in updating working memory. British Journal of Psychology, v. 85, p. 145-152, 1994.

Received: 2017/09/29

Approved: 2018/01/07

Contact:

Yael Neumann <ynslp@aol.com> 